\title{
Bioengineering and Hydromechanics of Flora in Stabilization of Slopes
}

\author{
${ }^{1}$ LYingluo Wang \\ ${ }^{1}$ Department of Mechanical Engineering, Xi'an Jiaotong University, Xi'an, Shaanxi, P.R. China. \\ ${ }^{1}$ lwangluo@mail.xjtu.edu.cn
}

\author{
ArticleInfo \\ Journal of Machine and Computing (http://anapub.co.ke/journals/jmc/jmc.html) \\ Doi : https://doi.org/10.53759/7669/jmc202101018 \\ Received 20 March 2021; Revised form 28 April 2021; Accepted 10 June 2021; Available online 05 July 2021. \\ (C)2021 The Authors. Published by AnaPub Publications. \\ This is an open access article under the CC BY-NC-ND license. (http://creativecommons.org/licenses/by-nc-nd/4.0/)
}

\begin{abstract}
This paper focusses on the hydromechanics of flora in the stabilization of soils. Slopes in rocks and soils are founding in physical and manmade conditions. Stockpiles, canals, levee, dams and highways are structured through the slopping of lateral faces in soils since a slope is typically cost effective compared to structuring walls. Physical forces e.g. water and winds transform the earth's topography and other planets, typically forming unstabilized slopes. Flora is considered one of the initiatives considered in the control and prevention of landslides that are shallow and ones occurring during rainy seasons. Vegetation application for the stabilization of slopes is identified as soil bioengineering. Knowledge of flora contribution, in this paper, will be reflected on a case area of Kedah (Northwestern part of Peninsular Malaysia). The aspect of bioengineering i.e. mechanical and hydrological aspects will be applied. The effects of hydromechanical of flora on the stability of slopes are to minimize the content of soil water through evapotranspiration, interception and transpiration. Mechanical implication of flora on slope stabilization is to stabilize slopes to reinforce it mechanically.
\end{abstract}

Keywords - Soil Bioengineering, Soil Stabilization, Hydromechanics.

\section{INTRODUCTION}

In this research contribution, the hydromechanics of soil, in the field of soil bioengineering, is critically analyzed. This paper will focus on providing critical understanding on the stabilization of manmade and physical slopes and would focus on defining the various forms of slopes and different groups of slope failures. This research will define and discuss slope configuration and different classes of slope failure to assess the present and novel solutions and design methodologies for enhancing the stability of soils. In this research, a normal slope failure was considered through an inspection of physical sites.

Flora's consumption of water varies with respect to density and age, types of soils and rainfall factors. Flora with the capacity to absorb more water from the soils and release into air through the process of transpiration will minimize the stress of pore water and develop the stability of slopes, and flora with deeper roots anchoring and stronger roots that binds was possibly fundamental to enhance stability of slopes. Rock falls, mudflows, slumps, slips and landslides are some of the terminologies utilized to define rock and soil movement under gravity influence. These forms of movement could be inconvenient; however, from time-to-time, they could cause significant damages.

Humans, for over many decades now, are aware of the disasters and hazards that come from processes of the earth's surfaces i.e. short-term and long-term climatic effects and flooding. The issues of slope stabilization are known widely across the globe too. Mass movements and landslides are fundamental and expensive hazards; and have attracted the attention of many geotechnical experts and geologists internationally, mostly in areas that face slope stabilization issues. Rocks and soils are typically found in both manmade and physical structures. Stockpiles, levees, highways and canals are structured by sloping the lateral face of soils since slops are normally inexpensive compared to the wall construction.

Physical forces e.g. water and winds transform the general earth's topography, which also affects other planets hence forming unstable slopes [1]. In that case, geotechnical experts have to concentrate on the drainage of the surface, groundwater, geology and the soil strength in the evaluation of soil stabilization. The evaluation of stability in soils is with respect to simplifying assumption and critical assessment of the site under issue. The failure of the slope is based on the type of soils, stratification of soils, groundwater, slope geometry and seepage. A typical form of slope failure is homogeneous fine-grained soil, rotating slides with rotational points on imaginary axes that are parallel the slopes. As evident from roads and highways constructions, flow slides occur whenever external and internal conditions force soils to act as viscous fluids and proceed to shallower slopes and flow in different directions. The slides of flow will happen in wet and dry soils.

The failures of soils are due to physical forces, misjudgment by humans, and burrowing activities by animals [2]. Earlier on, bioengineers and hydromechanics engineers used rock wall and concrete models to repair the slopes that had been excavated and embankments of roads. However, the overall costs for doing this was high and could also lead to more environmental hazards and problems. With respect to economic development, humans now paid much attention of 
environmental quality. As such, highways and roads engineers began to utilize bioengineering and hydromechanics techniques to safeguard roads, highways and slopes along these planes.

Mass movements in slopes typically happen during rainy seasons. Rain duration and intensity are major factors to consider in this case. Rainfall amount, which fundamentally affects the failure of slopes, is $\geq 68 \mathrm{~mm} /$ day in most soils that tend to absorb water quickly. Infiltrated water in the ground will sustain the pore spaces of soils and make the soils to be saturated hence leading to weaker aggregation of soils [3]. The conditions of soil saturation enhance the soil loads and might stimulate the movement of soils due to pushing pressure on the upper part of the slips, which is considered stronger compared to the retaining forces.

The triggering force in mountains is influenced by soil bulk density, load, rainfall intensity and steepness of slopes, including the availability of impermeable layers in the slopes. The application of flora on the stabilization of slopes is fundamental in bioengineering. Now, bioengineering was introduced to mitigate the issues of slope failures and erosion by vegetation as ground movement barriers, hydraulic pumps and hydraulic channels. Flora is a fundamental alternative initiative for bioengineering experts to prevent landslides and enhance the stability of slopes. The main role of vegetation is to control the movement of soil and it applicable for shallower landslide depths.

Bioengineering of soils utilizes certain features of flora components and incorporates particular features of structures with flora [4]. The resultant systems and elements have potential advantages and disadvantages, which have to be considered before choosing them for application. Firstly, we should consider the critical elements of flora (herbaceaous and woody species). Herbaceous flora, mostly forbs and grass, provide firm protection against wind and water on slopes under issue. These also provide minor protection over shallower mass movements. Flora aids in the prevention of surface erosion by (a) restraining and binding particles of soils in a single place; (b) minimizing transportation of sediments, intercepting drops of rains; (c) retarding the speed of surface runoff; (d) maintaining and developing infiltration capacity; and (e) minimizing the freeze and thaw cycle of soils. These are normally those that are susceptible to freezing herbaceous flora and those typically utilized in bioengineering of soils to add more protection to the surface erosion.

Woody flora that is significantly rooted provides more protection against shallower mass movement by biomechanically strengthening soils with roots, depleting soil waters through interception and transpiration, soil arching and buttressing actions from stems that have been embedded. Live fascine, for instance, provides numerous of these protective functions. These are fictitious from species that are woody, e.g. shrub dogwood and shrub willow, into the bundles that are sausage-like and those incorporated in stems arranged in a corresponding manner to the contour of the slops. This technique of orientation and placement will not be utilized in the reinforcement of slopes.

Live fascine act as a strength dissipater of downward moving waters through debris trapping and provides branch series on which transplants, seedlings and grasses establish with ease. Segments of Live fascine root with ease and become a portion of the stabilization cover. Live fascine leads to a prompt development of surface stabilization and can also enhance stabilities to depths of about $3 \mathrm{fts}$ according to the development of roots. For brush-layering, branches and woody species shoots eg privet, dogwood and shrub willows are added in layers with their steps and placed in perpendicular orientations according to the contours of the slope. These perpendicular orientations are optimal directions for maximized reinforcement in slopes. Brush layering can enhance the stability of soils to depths of about $5 \mathrm{fts}$.

The second most critical aspects to consider include the structural elements. Effectively designed and integrated structures aid in the stabilization of slopes against shallower mass movements and aids in the protection of slops against gully or rill formation. Structures are also fundamental in the establishment of flora on steeper slops or in parts that face more erosion. Structures potentially make it possible for the establishment of flora on steeper slopes. They also stabilize the slopes during critical times for root growth and seed germination. Without stabilization, flora would fail especially during vulnerable seasons.

Material structures can be developed from both manufactured and natural materials [5]. The natural materials, e.g. timber, stone, rocks, earth, are typically pocket-friendly, and compatible to the environment and effective for flora treatment compared to processed materials. Physical materials can also be present on the site, hence incurring no additional costs. Some of the structures have both processed and physical materials e.g. concrete cribwalls, steel-bin walls, polymeric and welded-wire geogrid wall, revetment or gabion walls and reinforced earth. In these instances, concrete and steel provide more rigidity, reinforcement and strength, whereby soil, rock and stone provide more mass. These forms of structures have more spaces, which are normally planted with woody or herbaceous flora.

Retaining structures are needed to stabilize and safeguard steeper slopes hence allowing for the grading of slopes back to stable angles, which can effectively be revegetated without land loss at the land crests. The structures are able to resist significant lateral earth forces and shear pressure than flora. Structures of grade stabilization are applied in the prevention and control of gully erosion. The structure of grade stabilization minimizes the grades that are above it and potentially dissipates more energy of water flow within individual structures. Sediments and debris are trapped and deposited upstream in these structures. This, therefore, allows the establishment of flora behind these structures that firmly stabilizes the earth.

Structures for grade stabilization range from segments of simpler woody check dam to more complex concrete overfall structures and embankments of the earth with pipe spillways. Gully controls provide the best example of the incorporation of flora and structures. A structural measure would be needed in short-term stabilization of slopes in critical environments. The long-term objective is to potentially maintain and establish flora cover, which could prevent erosion. The objective is rarely recognized unless for severe gully conditions, which can be altered with immediate effect. Vegetation, for instance, will infrequently strengthen and stabilize gully headcuts due to concentrated flows of water, pervasive pressures and overfalls, which develop gully enlargements in more channel systems that are unstable. Initially, flora and structures collaborate in an integrated manner. The critical role of structures is to aid in the establishment of slope that will provide long-term protection and stability. 
Section I has introduced the concept of bioengineering of soil and evaluated how structures and flora are needed for the stabilization of soils. The remaining sections of the research focus more on the hydromechanics of soil stabilization. In that case, the remaining part of the paper has been organized as follows: Section II present a background analysis of the research. Section III reviews the relevant literature sources. Section IV presents the methodology of the research where scale and reconfiguration of slopes; application and role of flora; and flora species on slope stabilization are critically evaluated. Section V focusses on the results and evaluation of geometrical techniques, drainage techniques and retaining structures techniques. Lastly, Section VI concludes the paper.

\section{BACKGROUND ANALYSIS}

This research contribution focuses on the comprehension of soil stability of both manmade and physical slopes. It will also focus on defining different slopes and the several groups of slope failures. This research contribution evaluates the relative slope configurations and their various slope failure segments, to potentially evaluate the present and novel remedial methods and design components for slope protection.

Firstly, analyses of normal slope failures will be done with reference to different sites. A field analysis will reflect on the various configurations of the slopes, their geometry and failures. Graphical analysis will be considered to potentially grope slopes and their respective failure cases. Several novel remedial methods have been visualized to be applicable in many residential areas in the world.

This research analysis shows that various cut slopes, including mild slopes, still fall even after a long time. There are various remedial techniques utilize for slope stabilization. According to our observation of a soil condition at Kedah, Northwest area part of Peninsular Malaysia District, the remedial technique is applicable in retaining slopes. A specific area i.e. Kedah, Northwest area part of Peninsular Malaysia, has been considered as an area undergoing significantly risky landslide activities. The remedial operations utilize several retaining structures for slope stabilization.

\section{LITERATURE REVIEW}

A. Kolichko and A. Andrianov in [6] have evaluated the construction of slopes and presented the basic theories concerning the different soil types. From the analysis, it is noted that stabilization techniques, soil movement and soil type related are factors to consider by soil bioengineers when focusing on the stability of soils. The construction of slopes is related to soils and it is fundamental to comprehend soil background and techniques for soil assessment, which have been in existence for the structuring of novel slopes and remedial for residential slopes.

M. Damavandi, P. Dixon and D. Pearsall in [7] argue that each slope has force that facilitates downward movement of slopes and the opposing stress resists movements. An overall definition of safety factor (F) of slopes result from the comparison of the down slopes and shear pressure with the shear strength of soils, alongside a known and assumed rupture surfaces. Based on this overall definition, B. Ahmed in [8] have grouped the causes of landslides into external causes resulting from the development of shear stress i.e. transition in the regime of water, drawdown, vibration or shocks, loads of slope crests, unloading slope toes and geometrical transitions, such as seepage erosion, weathering and progressive failures.

C. Jianwei, W. Yong, P. Qichao and J. Qing in [9] pointed the number of internal and external causes that might be working to minimize shearing resistance or to advance the shearing pressure. It was noted that there are some causes stimulating the safety factor and its ratio. A significant variety of slope movement reflects on the conditional diversity, which affects the slopes in becoming more unstable and the processes, which affect soil movement. It is best to evaluate causal factors, which include both the processes and conditions compared to those causes in every second. Therefore, the conditions from the ground (fracturing or weathering degree, sensitive fabrics and weak strength) are influential methodology; however, these are not causes. These are conditions essential for unstable development of slopes to which should be integrated the ecological methodology of stress, temperature and pore water stress.

N. Kotake, T. Tanaka, F. Tatsuoka and F. Peng in [10] argue that it does not matter if the ground is weaker since the aspect of failure will occur in case there is a fundamental cause process acting too. These causal processes could be anthropogenic or natural; however, fundamentally transform the static nature of the surface hence affecting the slope systems negatively. Seasonal evaporation and rainfall is reflected with respect to seasonal variation when it comes to the aspect of safety. In case of long-term trends of levels of groundwater or the respective transformation in slope strength as a result of weathering, these will be represented as trends that are imposed on seasonal variations. Sudden transformations will be because of short-term variations in material strength or stress applied to slopes.

T. Jamaluddin in [11] evaluated the factors provoking the slope failures. Wind and water endlessly erode physical and manmade slopes. Erosion transforms the geometry of slopes, fundamentally resulting to the failure in slopes and landslides, streams and rivers scouring their banks to undermine manmade and physical slopes. S. Nicholson in [12] argued that long rains erode, soften and saturate soils. Water has the capacity to penetrate soils into its cracks to weaken the soil layers that underlie hence causing slope failure; for instance mudslides.

R. Jibson in [13] evaluated the effects of earthquakes on slopes. Earthquakes stimulate dynamic stress, mostly the dynamic shear stress, which minimizes the shear stiffness and strength of soils. Pore-water force in soils that are coarse grained would amount to significant value, which is the same as the overall average force, which make these soils to act as viscous fluids. This aspect is referred to as dynamic liquefaction. Structures in these soils collapse, whereas some buried within them arise. The velocity in which dynamic stress is induced stops coarse grained soil from a draining much forces of water. Therefore, seismic failure even normally happens based on undrained conditions.

W. Benson in [14] evaluated the geographical features. Various failures typically result from unidentified environmental components. Thinner silt seam (some $\mathrm{mm}$ ), in thickness, based on thickened clay deposits can be ignored in drilled operations or assessment of borehole $\log$ to identify later on that the availability of silt led to catastrophic failures. Stratified soil and sloping are subjected to primitive slides alongside weak layers. Y. Wang in [15] evaluated 
external loads. Loads integrated on slope crests (of slope tops) add to gravitational loads and might affect the failure of slope. Loads included at toe, referred to berms, will enhance slope stability. Berms are normally utilized to remediate problematical slopes.

G. Tatarov and D. Bushman in [16] evaluated the construction activities that are closer to an existing slope. It is evident that construction activities can stimulate failure due to lateral resistance. We can effectively subdivide the failures of slopes because of construction activities into two different cases. One of the cases is the excavated slope and another case is filling slope. When the process of excavation occurs, the overall stress is minimized and the negative pore water pressures are integrated in soils. As time elapses, negative pore pressure of water potentially dissipates, affecting and diminishing fundamental forces and consequently minimizing shear force in soils. In case slope failures happen, they would happen after construction is finished.

Q. Zhang in [17] evaluated fill slope as typical in constructional embankments. Fills (soils) are incorporated on sites and compacted to a specification, normally more than $94 \%$. Soils are habitually unsaturated and the negative pores-water forces tend to be evident. Soils where fills are incorporated i.e. foundational soils might be saturated. In case the foundational soils are saturated, positive pores-water force could be generated with respect to the overall fill weight under the process of compaction. Stress effectiveness deceases whereas the shear stiffness diminishes. As time goes, positive pore-water pressure can dissipate. Therefore, stress and shear stiffness of soils increase significantly. As a result, the failure of slopes in fill slopes happen immediately after or during constructions.

Z. Li, L. Chai, C. Li and Y. Xu in [18] evaluated the rapid drawdown of water. It is evident that reservoir are subjected to more rapid drawdowns. In this instance, more lateral forces due to water are eliminated whereas more porewater forces are left with less sufficient time for dissipation. The overall effect is that slopes can fundamentally fail with respect to undrained situations, and forces of seepage, which affect slope failure.

\section{METHODOLOGY}

It is fundamental to comprehend the scale and configurations of slopes, including its dynamic conditions when assessing the real conditions of slopes and counter-measure designs. Even in complete slope structures, rational assessments and the relative countermeasures, which can effectively be programmed in the initial stages of the slopes, cannot easily be noticed. Hence, the overall tendencies of slopes can be identified through the estimation of configuration features: depth, length and width. For this aim, it is fundamental to categorize the connection between every feature from the evaluation of features of the present slopes. Based on this viewpoint, the connection between the slope configurations and scale of angles of slopes with respect to the examples that are retrieved from the site in which real condition e.g. depth and extent of sliding are identified.

Scale and Configuration of Slopes

The features of configuration of slopes can be illustrated as below:

- $\quad$ Slope width (W): Maximum slope width

- $\quad$ Slope depth (D): Maximum slide plane depth in vertical directions

- Slope length (L): Overall distances between toe and head of landslides

- Angle of the slope: Line inclination between the toe and head of slopes accordingly in a horizontal direction

Fig 1 and Fig 2 below represent the determination of features of configuration.

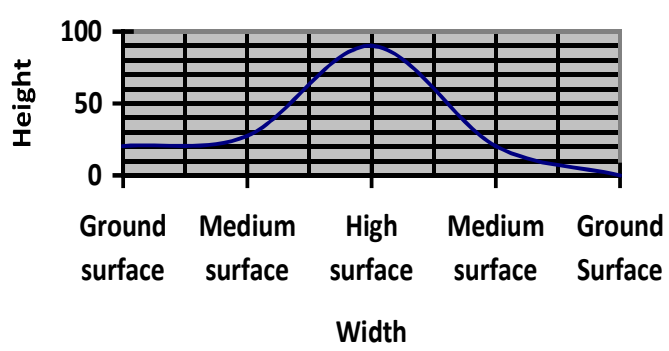

Fig 1: A graph of height against width

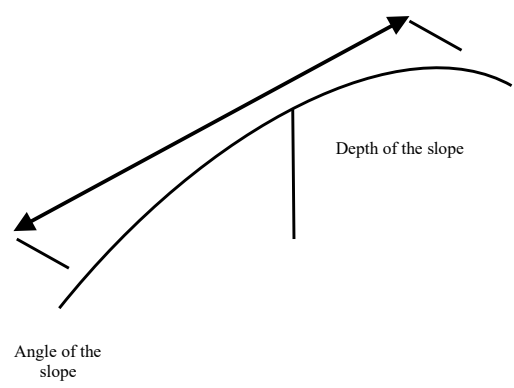

Fig 2: Determination of slope angle, depth and length of slopes 
The Application and Role of Flora

Flora in residential area i.e. Kedah, Malaysia (Northwest Peninsular), is used a mitigation for landslides in each slope strata. Slopes of about $1 \%$ to $19 \%$ are recommended for parkia speciosa and swietenia macrophylla. Calliandra, swietenia macrophylla, dalbergia penata, parkia speciose and leucaena leucephala are tress in hilly areas between $20 \%$ to $39 \%$ and steeper slopes that are more than 39\%. Agathis alba, aleurites moluccana, tectona grandis, cassia siamea, swietenia macrophylla, pinus mercusii and acacia villosa are the recommended trees. The impact of flora is to make slopes more stable with hydromechanics reinforcement of soil via the roots as its mechanical factor and hydrological implication (Table 1) with soil reduction of the content of water through the process of precipitation interception and transpiration. The knowledge of flora in this contribution is based on mechanical and hydrological aspects.

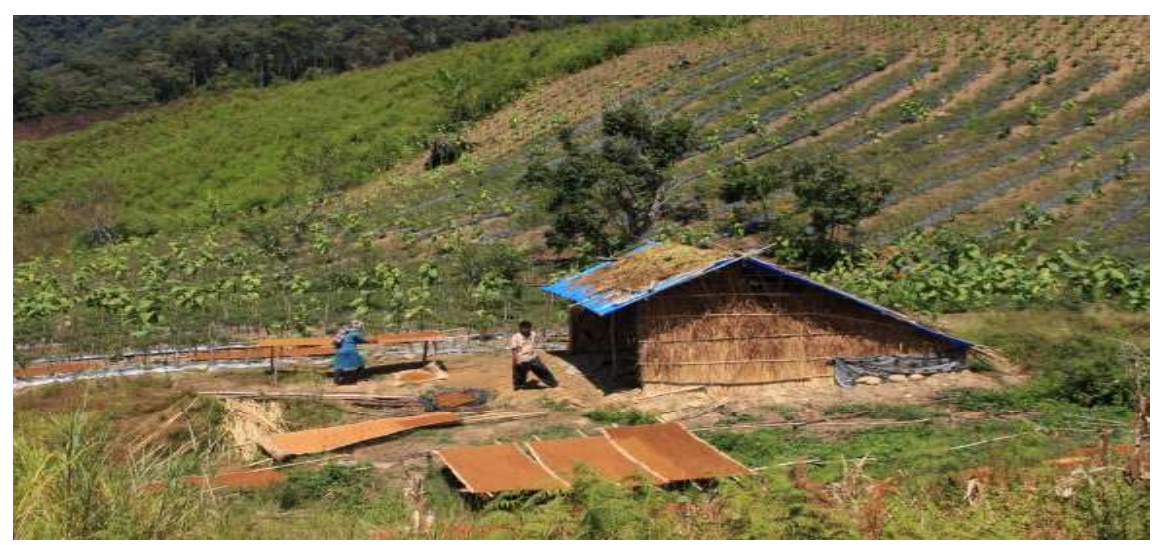

Fig: 3: Case residential area of Kedah, Malaysia

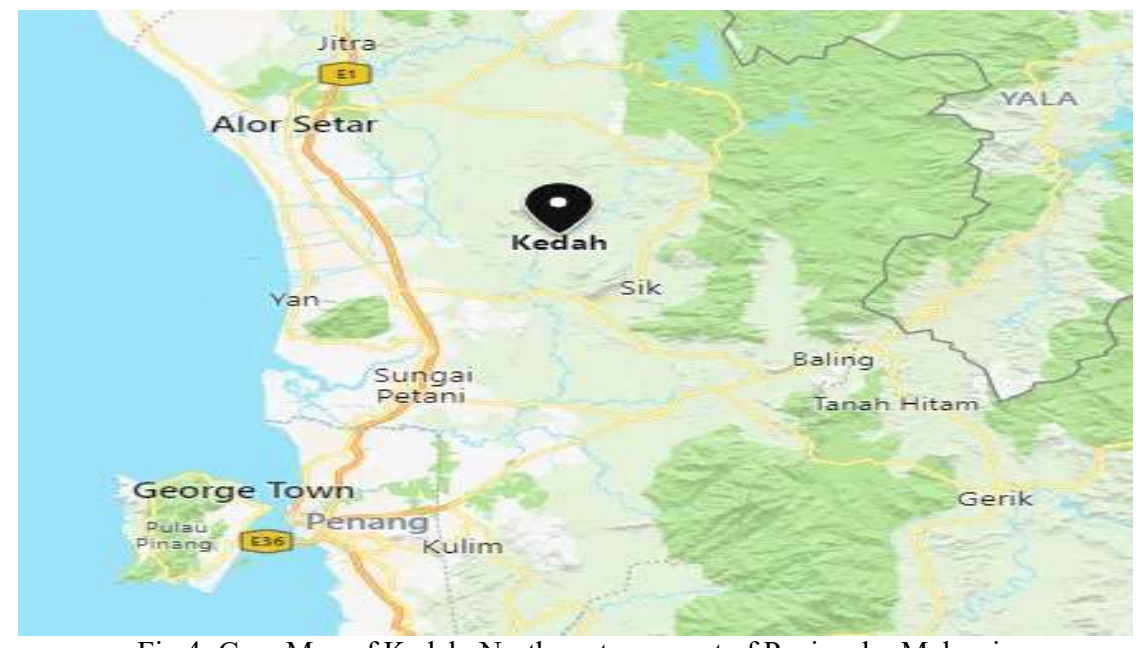

Fig 4: Case Map of Kedah, Northwest area part of Peninsular Malaysia

The advantageous mechanisms of slope stability are based on tree points such as roots and elements below the ground surface. Transpiration and evapotranspiration mechanisms of tree leaves act as holders of rainfall from penetrating deeper into the soils to maintain negative pore waters and force into the ground level. The higher the canopy density, the higher the capacity to catch rains in form of interception of water. Massive interception could minimize and delay rains to penetrate the surface of the soil. Shear force, integrated in the ground with respect to root tensile resistance, considers carrying out mechanical reinforcement of soils by roots. The condition of roots is obliged to hold the layers of soils. More fibrous root concentration facilitates stronger holds of soils. Soil shear-force magnitude is stimulated by the condition of the soil (porosity, fraction of clay and moisture) and flora rooting features. The roots of trees will advantage the shear force of the soils through tensile force of individual roots and give slope sheering resistance after or during heavy rains on landslides that are shallow.

The tree stem is obliged to assure stability. The process of infiltration results to the availability of perched waters on the boundary of two various permeable materials. This increases the pressure of soil pores and provides more stress to mass movement of soil. More water infiltration into soils mass via scars from uprooted trees can therefore minimize the resistance of soil mass to slope failures. The pressure of wind on the tree can also provide destabilizing moments in case trees are not anchored effectively. This definitely leads to the failure of slopes. Roots are capable of providing effective connections between the particles of soils in the soils body (surface tensile forces) that amount in cementation pressures on the soil masses. 
Table 1: Hydrological implication of flora

Hydrological Mechanics

\begin{tabular}{ll}
\hline $\mathbf{1}$ & $\begin{array}{l}\text { Soil moisture depletion by root absorption might potentially accentuate soils in } \\
\text { the cracks hence increasing the capacity of infiltration. }\end{array}$ \\
$\mathbf{2}$ & $\begin{array}{l}\text { The roots can absorb moisture from soils and released into the atmosphere via the } \\
\text { process of transpiration, which leads to a decrease of pore water. }\end{array}$ \\
$\mathbf{3}$ & $\begin{array}{l}\text { Stems and roots increased roughness to soil permeability and ground surfaces to } \\
\text { expand the capacity of infiltration. }\end{array}$ \\
$\mathbf{4}$ & $\begin{array}{l}\text { Foliage can potentially intercept rains hence causing evaporative and absorptive } \\
\text { losses, which minimize rains. }\end{array}$ \\
$\mathbf{5}$ & $\begin{array}{l}\text { Roots bind particles of soils together and minimize their susceptibility to the } \\
\text { process of erosion. }\end{array}$ \\
$\mathbf{6}$ & $\begin{array}{l}\text { Plants can expose to winds transmission of dynamic forces in soils. } \\
\mathbf{7}\end{array}$ \\
$\mathbf{8}$ & $\begin{array}{l}\text { Weights of flora surcharge slopes and enhance downhill and normal components } \\
\text { of forces. } \\
\text { though arching and buttressing. }\end{array}$ \\
\hline
\end{tabular}

Flora Species on Slope Stabilization

Because of the hydrological implication of flora, as seen in Table 1, transpiration is considered a parameter for the consumption of tree water. Roots have the potential to absorb water from soils and produce it into the atmosphere through the process of transpiration, which minimizes the stress in pores. The consumption of tree water varies in every species type and this is based on age, plant density, soil types and rainfall factors. Evapotranspiration rate and the general percentage of rainfall for each species is $1500 \mathrm{~mm}$ for eucalyptus, $1200 \mathrm{~mm}$ for acacia, $700 \mathrm{~mm}$ for albizia chinensis, 680 $\mathrm{mm}$ for melalenca $560 \mathrm{~mm}$ for swietenia macrophylla and $490 \mathrm{~mm}$ for celophyllum.

Table 2 below represents the overall amount of varying rate of evapotranspiration in various forms of flora with respect to density and age of the plant, soil type and rainfall factors. Acacia mangium is known to have high evapotranspiration rate than other types of tree species. On the other hand, Schima wallichi is considered to have the smallest rate of evapotranspiration. The loss of water in Pinus forest interception is considerably higher (16\%) compared to agathist forest $(15 \%)$ and Wallichi Schima (14\%). The rate of evapotranspiration in Pellita Eucalyptus forest in the Province of Rian is $4.6 \mathrm{~mm}$ per day or approximately $73 \%$ of rains.

Moisture in soil decreasing by flora could potentially minimize the pore water force in the mantle of soils on physical slopes thus enhancing stability. The top part of the step includes both beneficial and adverse effects. Flora weight can develop the stability of the slope due to the fact that is subjects the slope to more stress, mostly the plants with significantly shallow roots, which adds loads to a hill. Thus, steeper slopes necessitated flora with larger and deeper fibre roots to enhance the stability of the slope. Pinus normally has deeper roots genetically; in that case, its roots are able to penetrate to deeper layers, and it include relatively lightweights, which is capable of maintaining the stability of the slope since it can minimize the slope loads. Dillenia suffruticosa, Leucaena leucocephala and acacia mangium are the species that have the best capacity as slope plants with respect to their shear firmness and root features. Acacia in this case has a higher shear force than Dillenia suffruticosa and leucaena leucocephala.

Researchers have presented that Acacia has a higher shear firmness value i.e. $30 \mathrm{kpa}$ and $50 \mathrm{kpa}$ at a load of 13 to 24 $\mathrm{kpa}$. In addition, the test of tensile strengths indicated that leucaena leucocephala strength has higher tensile forte compared to Malabathricum and acacia. Its significance to the improvement function in the stabilization of slopes is based on the features of root systems and soil conditions e.g. tensile strength and distribution of roots.

Table 2: Rate of evapotranspiration of different species of trees

\begin{tabular}{|c|c|c|c|c|}
\hline Species of trees & $\begin{array}{l}\text { Time } \\
\text { research } \\
\text { (years) }\end{array}$ & $\begin{array}{l}\text { Rains mm per } \\
\text { year }\end{array}$ & $\begin{array}{l}\text { ET mm per } \\
\text { year }\end{array}$ & $\begin{array}{l}\text { ET \% of the } \\
\text { rains }\end{array}$ \\
\hline Altingia excels & 1 to 3 & 3.4 & 1.4 & 41 \\
\hline Acacia ducurens & 1 to 3 & 3.4 & 1.5 & 45 \\
\hline
\end{tabular}




\begin{tabular}{|c|c|c|c|c|}
\hline $\begin{array}{l}\text { Callothirsus } \\
\text { Calliandra }\end{array}$ & 1 to 3 & 3.4 & 1.5 & 43 \\
\hline Dalbergia latifolia & 1 to 4 & 3.7 & 1.4 & 42 \\
\hline Shorea punanga & 1 to 4 & 3.7 & 1.2 & 33 \\
\hline Acacia mangium & 1 to 4 & 3.7 & 2.4 & 68 \\
\hline Eucalyptus trainta & 1 to 3 & 3.1 & 1.7 & 53 \\
\hline Eucalyptus alba & 1 to 3 & 3.1 & 1.6 & 52 \\
\hline Eucalyptus deglupta & 1 to 3 & 3.1 & 1.6 & 53 \\
\hline $\begin{array}{l}\text { Swietenia } \\
\text { macrophylla }\end{array}$ & 1 to 6 & 4.0 & 1.7 & 58 \\
\hline Schima wallichi & 1 to 8 & 3.0 & 2.3 & 23 \\
\hline $\begin{array}{l}\text { Eucalyptus } \\
\text { urophylla }\end{array}$ & 1 to 8 & 3.0 & 1.7 & 37 \\
\hline Pinus merkusii & 1 to 8 & 3.0 & 1.1 & 65 \\
\hline
\end{tabular}

Acacia tree with the vetivers grass are the species of plants, which can be integrated in the stability of soils. Shearing resistance of Acacia with roots of flora are capable of reinforcing soils with high shear strength. Vetivers grass by $85 \%$ in a period of two months can increase to $165 \%$ in 1.5 years. Flora is considered to have higher tensile strength and typically have roots that are deep compared to shrubs. Therefore, developing the reach of reinforcement in soils is possible.

From this research, it can be argued that $5 \mathrm{~m}$ trees (deeply rooted) can provide higher factor-of-safety (See Table 3 ).

Table 3: Factor-of-safety in shrub and tree slopes

\begin{tabular}{lll}
\hline $\begin{array}{l}\text { Degree of the slope } \\
\text { gradient }\end{array}$ & \multicolumn{2}{c}{ Factor-of-Safety (FOS) } \\
\cline { 2 - 3 } & Tree root $(5 \mathrm{~m})$ & Shrubs \\
$\mathbf{2 1 . 1}$ & 2.4 & 2.1 \\
$\mathbf{5 0 . 0}$ & 1.1 & 0.9 \\
\hline
\end{tabular}

The species of trees, which can be chosen in stopping landslide based on the rooted value of binding and anchoring index as indicated in Fig 3 and 4. Vertical and horizontal roots have been utilized to evaluate the anchoring and binding of root index with respect on the ratios of vertical or horizontal root diameters based on the diameter of the tree. The features of flora roots influencing the shear strength of soils include root strength, gravity, diameter and distribution. The higher the root value root binding and anchoring the flora, the more fundamental the possibility to enhance slope stabilization.

Flora is considered as a fundamental initiative in the mitigation of shallower landslide issues. Plant application for the stability of slopes is mechanical and hydrological aspect in what is known as hydromechanics. Hydrological data of flora is flora canopy of transpiration and interception, and the process of evapotranspiration, which can minimize rainfall amount until the moment the root systems and surface absorb water and develop the shear force in soils. As for the mechanical aspect, anchoring aspect of roots and binding index have to be considered as well. Table 4 shows the root binding and anchoring index of the respective species of trees.

\section{RESULTS}

There are various techniques used for slope stabilization in many residential areas. With respect to the various observations made at Kedah, Northwest area part of Peninsular Malaysia district, several tech niques have been noted. There are three fundamental groups of mitigation measures to be considered:

\section{Geometrical Techniques}

The geometrical techniques are the most usual methods, which are utilized in most residential areas of Kedah, Northwest area part of Peninsular Malaysia. This technique is typically simpler and pocket-friendly. The transformation of the slope angle from steeper to gentle slope might enhance the degree of slope stabilization and slope angle and the bonding of grass in soils typically supports this. The residential parts have been integrated on a wide area to create space for remedial works. The conventional technique of grading the slope angle necessitates excavation activities. However, such techniques does not necessitate high loads resistance and physical stabilization of slopes using creepy surfaces of grass. This technique is widely utilized in the Kedah, Northwest area part of Peninsular Malaysia district and necessitates minimal costs of maintainability. Some of the residential areas have also combined this technique to retain some building structures at slope toes. This approach, nonetheless, might also be the same as Structure retaining technique, surface drainage, and geometrical technique. 
Table 4: Root binding and anchoring index for various species of trees

\begin{tabular}{|c|c|c|c|c|}
\hline Species of trees & $\begin{array}{l}\text { Index of root } \\
\text { anchoring }\end{array}$ & Class & $\begin{array}{l}\text { Index of root } \\
\text { binding }\end{array}$ & Class \\
\hline Gyrinops verstigii & 0.9 & Medium & 1.0 & Low \\
\hline $\begin{array}{l}\text { Callophylum } \\
\text { inophylum }\end{array}$ & 2.2 & High & 1.0 & Low \\
\hline Mangifera indica & 1.4 & High & 4.0 & High \\
\hline Achras zapota & 1.0 & Medium & 2.0 & Medium \\
\hline Lansium sp & 1.3 & High & 4.0 & High \\
\hline $\begin{array}{l}\text { Garcinia } \\
\text { mangostana }\end{array}$ & 0.9 & Medium & 2.0 & Medium \\
\hline Arthocarpus altilis & 0.8 & Medium & 1.9 & Medium \\
\hline Gretum gnemon & 2.2 & High & 1.5 & Low \\
\hline Nephelium lapaceum & 1.1 & High & 3.8 & High \\
\hline $\begin{array}{l}\text { Artocarpus } \\
\text { heterophyllus }\end{array}$ & 1.4 & High & 3.5 & High \\
\hline Persea Americana & 1.4 & Tinggi & 2.1 & Medium \\
\hline Durio zibethinus & 1.1 & High & 0.9 & Low \\
\hline Aleuritas moluccana & 0.7 & Medium & 1.6 & Medium \\
\hline
\end{tabular}

\section{Drainage Techniques}

One of the factors influencing the failure of slopes is power water force and saturation pressure, which build up in subsoils. In case the systems of drainage have been provided, the possibilities of developing power water force and subsoils saturation can be minimized. This approach is effective. Nonetheless, the systems of drainage can be maintained with ease for better performance. It is easier to effectively maintain drainage of the surface; however, it can be challenging to maintain the drains hydrological implication.

Drains in subsoils are mostly identified in retaining structures as weep holes technique and the cut-off drains. Generally, this technique is applied based on the combination of other fundamental techniques. Surface drains were utilized mostly with the geometrical techniques whereas subsoil drains are a part of this approach integrated with retaining structures. Surface drains are able to discharge water, mostly during heavier rainfall to mitigate the implication of significant amounts of water absorption on slopes.

\section{Retaining Structures Techniques}

This technique is expensive, in general. Nonetheless, because of the aspect of flexibility in the constrained location, it is typically an adopted technique for slope stabilization. The basis of this approach is to use the retaining natures to minimize downward force of soil masses. The retaining structures incorporate the gravity forms of retaining walls, contiguous bore piles, cantilever walls, steel sheet piles and cassion piles. The ground anchor and other forms of tie back schemes can be utilized with the retaining structure in case the driving force is significantly higher for resistance to occur.

This technique also incorporates rigid protection of the slope surface as stone pitching, masonry and shotcrete. Shotcretes are applied mortar on the surface of the slope by particular degree of thickness. Stone pitching and masonry would potentially stabilize slopes to mitigate the issue of slope failure at the face slopes. It might also minimize infiltration of water and minimize slope erosion of slope formation material. Slopes will be more stable whenever the section angle (profile) is maintain before the repose angle. Repose angle signifies an angle, which can maintain physically to a safer equilibrium based on the composition of slope materials. This surface angle can deviate from various materials with respect to material nature, particle sizes and compaction sizes.

\section{CONCLUSION}

In the hydromechanics of slope stabilization, slopes would be viewed to be stable if the force of shear in soils is considered a force-retaining factor when the surface of the earth has been tilted at a particular angle. Geostatic force incorporates the vertical and horizontal force or lateral force. The loads imposed incorporate the load structure of the soils, which are on the sloping soils or loading in the neighborhood. Soils can reduce or act as the bonding force between various particles of the soil. In case stress exceeds the soil shear force, landslides are witnessed. In addition, the developments in the upstream segment will cause water increase in the downstream hence facilitating slope failures. Water flows can be flowed effective when retention ponds and drainage systems are constructed.

This paper has evaluated the aspect of mechanical and hydrological factors, which are significant in the stabilization of slopes. In the result segment, various techniques have been considered relevant for the stabilization of soils and 
mitigation of slope failure issues. Slope surface configuration presents an idea for that retains the structure designs evaluated as techniques to curb slope failures. However, before applying a particular technique, it is fundamental to identify the initial factors that led to slope failure and instability. As a factor of soil stress, for instance, i.e. horizontal and lateral stress, climatic conditions i.e. humid or hot, could lead to slope failure.

\section{References}

[1]. C. Vérard, "Statistics of the Earth's Topography", OALib, vol. 04, no. 06, pp. 1-50, 2017. Available: 10.4236/oalib.1103398.

[2]. E. Botero, E. Ovando and M. Mendoza, "Successful prediction of slope failure in an excavation trial", Engineering Failure Analysis, vol. 109, p. 104392, 2020. Available: 10.1016/j.engfailanal.2020.104392.

[3]. A. KOWALSKI, D. KASZA and J. WAJS, "Structural control of mass movements on slopes formed of magmatic and metamorphic rocks: the case study of Wielisławka Mt. (SW Poland, Sudetes Mts.)", Geological Quarterly, vol. 63, no. 3, 2019. Available: 10.7306/gq.1482.

[4]. C. Lavaine, A. Evette and H. Piégay, "European Tamaricaceae in Bioengineering on Dry Soils", Environmental Management, vol. 56, no. 1, pp. 221-232, 2015. Available: 10.1007/s00267-015-0499-8.

[5]. N. Koratkar and K. Wang, "Special Issue on Nanostructured Material Systems and Structures", Journal of Intelligent Material Systems and Structures, vol. 17, no. 3, pp. 189-189, 2006. Available: 10.1177/1045389x06061952.

[6]. A. Kolichko and A. Andrianov, "Stability of slopes of construction cuts in rubble soils", Hydrotechnical Construction, vol. 16, no. 8, pp. 452455, 1982. Available: $10.1007 / \mathrm{bf0} 1539893$.

[7]. M. Damavandi, P. Dixon and D. Pearsall, "Ground reaction force adaptations during cross-slope walking and running", Human Movement Science, vol. 31, no. 1, pp. 182-189, 2012. Available: 10.1016/j.humov.2011.06.004.

[8]. B. Ahmed, "The root causes of landslide vulnerability in Bangladesh", Landslides, 2021. Available: 10.1007/s10346-020-01606-0.

[9]. C. Jianwei, W. Yong, P. Qichao and J. Qing, "Research on Proper Height of the New External-shearing and Internal-framing Structure", IOP Conference Series: Earth and Environmental Science, vol. 304, p. 032107, 2019. Available: 10.1088/1755-1315/304/3/032107.

[10]. N. Kotake, T. Tanaka, F. Tatsuoka and F. Peng, "Numerical Simulation of Bearing Capacity Failure in Reinforced Sand Ground and Slope", Proceedings of geosynthetics symposium, vol. 12, pp. 45-54, 1997. Available: 10.5030/jcigsjournal1995.12.45.

[11]. T. Jamaluddin, "Human factors and slope failures in Malaysia", Bulletin of the Geological Society of Malaysia, vol. 52, pp. 75-84, 2006. Available: $10.7186 /$ bgsm52200611.

[12]. S. Nicholson, "Short Rains and Long Rains", Eos, vol. 98, 2017. Available: 10.1029/2018eo076421.

[13]. R. Jibson, "Methods for assessing the stability of slopes during earthquakes - A retrospective", Engineering Geology, vol. 122, no. 1-2, pp. 43-50, 2011. Available: 10.1016/j.enggeo.2010.09.017.

[14]. W. Benson, "Notes on the Geographical Features of South-Western New Zealand", The Geographical Journal, vol. 86, no. 5, p. 393, 1935. Available: $10.2307 / 1786372$.

[15]. Y. Wang, "Study on deformation law of slope foundation under different external loads", IOP Conference Series: Earth and Environmental Science, vol. 358, p. 042053, 2019. Available: 10.1088/1755-1315/358/4/042053.

[16]. G. Tatarov and D. Bushman, "Use of hydraulic mechanization for clearing away the gorge slopes at the construction site of the Toktogul hydroelectric station", Hydrotechnical Construction, vol. 5, no. 10, pp. 908-912, 1971. Available: 10.1007/bf02403977.

[17]. Q. Zhang, "Analysis and Study on Slope Stability of High Fill Subgrade", Advanced Materials Research, vol. 919-921, pp. 637-640, 2014. Available: 10.4028/www.scientific.net/amr.919-921.637.

[18]. Z. Li, L. Chai, C. Li and Y. Xu, "Research on Stability of Slope by Influence of a Rapid Drawdown of Water Table", Advanced Materials Research, vol. 671-674, pp. 109-112, 2013. Available: 10.4028/www.scientific.net/amr.671-674.109. 